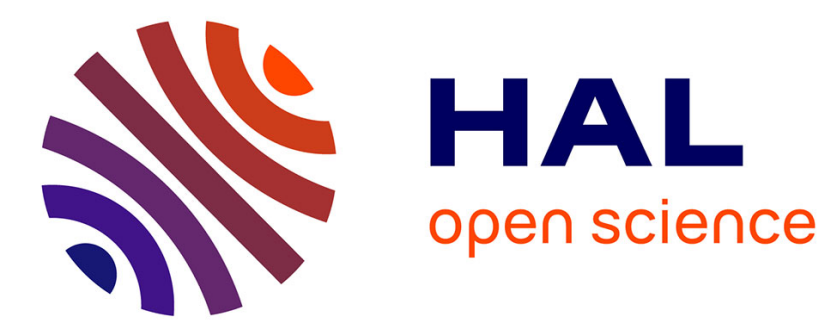

\title{
(Dis)aligning for improving mutual understanding in talk-in-interaction
}

Roxane Bertrand, Aurélie Goujon

\section{To cite this version:}

Roxane Bertrand, Aurélie Goujon. (Dis)aligning for improving mutual understanding in talk-ininteraction. Revue Française de Linguistique Appliquée, 2017, 2017-2, pp.53 - 70. hal-01653325

\section{HAL Id: hal-01653325 \\ https://hal.science/hal-01653325}

Submitted on 4 Dec 2017

HAL is a multi-disciplinary open access archive for the deposit and dissemination of scientific research documents, whether they are published or not. The documents may come from teaching and research institutions in France or abroad, or from public or private research centers.
L'archive ouverte pluridisciplinaire HAL, est destinée au dépôt et à la diffusion de documents scientifiques de niveau recherche, publiés ou non, émanant des établissements d'enseignement et de recherche français ou étrangers, des laboratoires publics ou privés. 


\title{
(Dés)aligner pour améliorer la compréhension mutuelle en interaction
}

\section{(Dis)aligning for improving mutual understanding in talk-in-interaction}

Roxane Bertrand (Aix Marseille Univ, CNRS, LPL, Aix-en-Provence, France)

Aurélie Goujon (Aix Marseille Univ, CNRS, LPL, Aix-en-Provence, France)

\begin{abstract}
This article deals with the mutual understanding phenomenon and its explicit marks in talkin-interaction. Drawing on conversation literature, we attempt to enhance knowledge about understanding by linking it to the alignment concept (Pickering \& Garrod 2004; Stivers 2008). This allows us to shed light on the different levels of understanding required for the accomplishment of successful interaction. Feedback responses provided by recipients are one of the explicit marks for achieving understanding. However, we focus here on dispreferred responses that can be considered a cue of disalignment, i.e. a break in the activity in progress and a potential indicator of trouble in understanding. Using the Conversational Analysis framework, we show how and why recipients can disalign and to what extent the mutual understanding is impacted by this disalignment.
\end{abstract}

Keywords: mutual understanding, (dis)alignment, dispreferred response, interactional activity

\section{Résumé}

Cet article est consacré aux marques explicites de la compréhension mutuelle dans l'interaction. Inspirées par la littérature conversationnelle, nous tentons d'améliorer notre connaissance sur la compréhension en l'articulant au concept d'alignement (Pickering \& Garrod 2004 ; Stivers 2008). Celui-ci peut renvoyer à différents niveaux de compréhension requis pour réussir l'interaction. Les réponses des destinataires sont l'un des indices explicites pour manifester la compréhension. Cependant, nous focalisons ici sur les réponses non préférées, possiblement indices de désalignement, à savoir arrêt dans l'activité en cours et indicateur potentiel de trouble dans la compréhension. Dans le cadre de l'Analyse Conversationnelle, nous montrons comment et pourquoi les participants peuvent désaligner et jusqu'à quel point la compréhension mutuelle peut en être affectée.

Mots-clés: compréhension mutuelle, (dés)alignement, réponse non préférée, activité interactionnelle

\section{Introduction}

We discuss here the "alignment/disalignment" phenomenon required for achieving successful communication in talk-in-interaction. To succeed, participants need to understand each other. From a psycholinguistic point of view, alignment facilitates comprehension: In the Interactive Alignment account (Pickering \& Garrod 2004), when 
participants align, they tend to imitate each other. Garrod and Pickering $(2009,298)$ argued that "comprehension involves imitating what has been heard using the production system, and then using those representations to make predictions". From a linguistic point of view, for Conversation Analysis researchers, understanding is not considered a "cognitive, private, individual phenomenon" but a collaborative one involving "situated, contingent, embodied, and intersubjective dimensions" (Mondada 2011, 542). Mutual understanding is then considered a collaborative achievement that the concept of alignment enables us to address in a relevant way : On the one hand, participants tend to align their mental representations by imitating each other at different linguistic and non linguistic levels of representation (referential, phonological, postural among others) (Garrod \& Pickering 2009); On the other hand, alignment also relates to cooperation at a structural level "by facilitating the proposed activity or sequence; accepting the presuppositions and terms of the proposed action or activity" (...) (Stivers et al. 2011, 21). In the present paper, we will take into account this under-studied area of structural level of alignment for a better understanding of mutual understanding in talk-in-interaction. As already said, an interaction would be successful when participants achieve alignment. Structurally, more specifically, an aligning response in storytelling conversation for example could be a 'mh' or 'yes' whereby the recipient allows the main speaker (storyteller) to achieve several turns for telling (Stivers 2008; Guardiola \& Bertrand 2013; Bertrand \& Espesser 2017). Providing another type of response - an unexpected one - , could be considered a cue of disalignment, i.e. a break in the activity in progress and a potential indicator of trouble in understanding. Our question is how and why recipients disalign and to what extent the mutual understanding is impacted by this disalignment? Using the sequential approach of the Conversation Analysis (Now CA) framework, we examine several sequences displaying disalignment cues - both verbal and non verbal - in different interactional tasks or activities.

\section{Overview}

How people coordinate is one of the fundamental issues of language use (Clark 1996). An example of such coordination is the turn-taking system (Sacks et al. 1974) that illustrates how understanding each other and understanding what is going on in the interaction enable participants to predict and provide a potential turn alternation within the appropriate timing. Achieving coordination requires aligning that improves (mutual) understanding. This issue raises a great interest in different fields. Psycholinguistics for example focuses on cognitive mechanisms involved in the understanding process (see Pickering \& Garrod 2004, among others). These cognitive aspects are out of scope here. Conversation Analysis studies are more often concerned not with understanding in itself but rather "in the basic methods through which understanding is established and maintained" (Koschmann 2011, 436). More specifically, Mondada claims: "understanding is not treated as a mental process but is related to the next action achieved by the co-participant and demonstrating her understanding" $(2011,543)$. This illustrates the way in which this notion has often been 
treated. Indeed, it fits with the objective and method of CA researchers that consist in examining how participants, turn-by-turn, incrementally, construct interaction in a collaborative way that of course requires understanding yet without focusing on it. Similarly, we are questioning how participants, thanks to explicit marks of alignment/disalignment, communicate to each other recognizable mutual understanding related to different levels of participants' coordination.

Before giving a brief overview of the Conversation Analysis literature examining how explicitly participants achieve understanding, it is noteworthy that it is not always easy to investigate it insofar as it is very often achieved tacitly (Mondada 2011, 544). This can partly explain why once we consider the issue of understanding, issues of misunderstanding are immediately brought up, both being different faces of the same phenomenon, but also maybe because the more explicit marks of misunderstanding make the latter a better candidate for analysis. However, except tacit understanding cases, Sacks (1992) distinguished two ways for explicitly showing understanding: Recipient can "claim" understanding by using a simple repeat of the prior turn or he can "demonstrate" it by using reformulation. Here again Mondada (2011) notes that this demonstration can also provide evidence of a misunderstanding since it can initiate a repair ${ }^{1}$.

More generally, achieving a mutual understanding requires to provide appropriate responses that allow the interaction to go on. Different alternative responses are possible among them a preferred/dispreferred one. This issue of preference has been largely investigated at a sequential level, particularly in adjacency pair sequences: for example in response to a question or an offer, an answer and an acceptation respectively are the preferred responses. Understanding also means predicting and anticipating, hence the importance of expected responses as preferred ones. Feedback items are one of the most studied expected responses of mutual understanding. Feedback items, also called "verbal listener response" (Dittman \& Llewellyn 1968), "backchannel response” (Yngve (1970), “acknowledge acts" (Sinclair \& Coulthard 1975), “minimal feedback” (Holmes 1997), “minimal responses” (Fishman 1983), “receipt tokens” (Atkinson 1992) (see Gardner 2001 for a more exhaustive list) have been investigated in different research fields (Allwood et al. 2007; Bunt 1994 in semantics; Gravano \& Hirschberg 2011 in prosody; Ward \& Tsukahara 2000 in Natural Language Processing; Clark \& Fox Tree 2002 in psycholinguistics). Whatever the framework, it is generally admitted that this type of behavior "appears to provide the auditor with a means for participating actively in the conversation, thus facilitating the general coordination (we highlight) of action by both participants" (Duncan \& Fiske 1977, 202-203).

The substantial literature on feedback responses has been directed towards their form ( $m h$, yeah, oh, repetition, nod, eyebrow movement) and their functions (continuer, acknowledgement, change-of-state token, confirmation request) as well as their sequential

\footnotetext{
${ }^{1}$ Repair is defined by Schegloff (1977) as "the set of pratices whereby a co-interactant interrupts the ongoing course of action to attend to possible trouble in speaking, hearing or understanding the talk".
} 
environment. In the 1980s, after establishing the now well-known continuer versus assessment dichotomy, Schegloff (1982, 87-88) said that continuers (mostly including Mm,

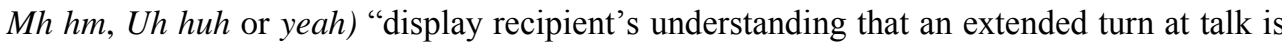
in progress but not yet complete, while simultaneously collaborating in the achievement of that multi-unit utterance by passing the opportunity to either (a) produce a more extended turn of their own or (b) initiate repair on the talk just heard". On the other hand, assessments refer to brief tokens such as "wow", great", "wonderful" and so on. They are designed to provide a form of appreciation that " $\mathrm{Mm}$ " for example cannot provide. Following Goodwin:

Assessments can occur in roughly the same environment as 'uh huh,' for example in the midst of extended turns at talk by another. However they are not treated like 'uh huh' by speaker, and indeed appear to have a different sequential organization. Briefly, rather than bridging two turn-constructional units (as with continuers, added by us) assessments in the midst of another's extended talk come to completion before a new unit is entered (1986, 209).

By investigating a larger project such as storytelling, Stivers (2008) allows us to expand the notion of preferred response to a broader span dealing with a level of alignment mainly concerned with the structural level of activity or action. For example, storytelling is an asymmetrical activity involving a main speaker (storyteller) who needs several turns to achieve his/her project and a recipient. Several studies have shown that feedback responses or continuers such as "mh", "yeah", "nod" for the most frequent, were preferentially produced at the beginning of stories by recipient (Bavelas et al. 2000; Stivers 2008; Guardiola \& Bertrand 2013; Bertrand \& Espesser 2017). In doing so, the interlocutor aligns with the current activity: Firstly, by accepting to become recipient of the story; Secondly, by providing such minimal responses as the story progresses, he/she explicitly gives cues of the elaboration of the common ground. Thus, these minimal responses provide evidences of the recipient's understanding while revealing a form of 'preference for progressivity' (Stivers \& Robinson 2006).

Sacks (1992) shed light on "understanding positions", i.e. specific sequential environments within talk for "doing understanding". For the author, the completion of a story is an example of such a position, "where recipients can exhibit their possible understanding, for example by using a proverbial expression” (1992, II, 426). Similarly, by using the concept of "affiliation" dealing with the expression of stance (mood, emotions, and so on) Stivers (2008) has shown that assessments, unlike continuers, would appear at the end of the story preferentially, when recipients have sufficient information for understanding and expressing a more evaluative response.

An interaction would thus be successful when participants align and understand each other. Consequently, a dispreferred response could be considered a cue of disalignment, i.e. a potential indicator of trouble in understanding. Let us go back to the point concerning the 'understanding position'. This deals with the localization and timing of responses. Indeed, it is noteworthy that a response occurring too early or too late in the activity in progress 
could reveal a disalignment and a problem in understanding (Stivers 2008; Selting 2017). In such cases, the lack of ratification by the main speaker provides evidence of a potential understanding problem (Bertrand \& Priego-Valverde 2017).

This paper is designed to investigate feedback responses as potential triggers of disalignment. After examining where and why these responses can appear, we will see that disalignment, more specifically at structural level, can be a mean for repairing or preventing a problem in understanding but also a mean for exhibiting another level of understanding dealing with the intersubjectivity level that does not really lead to a misunderstanding.

\section{Aims, Data and Methodology}

Talk-in-interaction implies that people are engaged in different types of activities such as explaining, storytelling, making others laugh, and so on. Following Lindström and Sorjonen (2014, 353), "any given response is shaped by at least the following: (i) the sequential place in which affiliation - (we replace by alignment in the present work) - is to be displayed, (ii) the type of action to which the response should be given, and (iii) the larger activity in progress".

Based on several extracts involving explanation and storytelling, we will show what typical feedback responses say about mutual understanding, when they structurally and punctually disalign (in terms of sequential environment) within the larger activity in which they are embedded.

Our following analysis is based on two French audio-video corpora recorded in the 'Parole et Langage' laboratory (LPL).

\section{The French Map-Task corpus}

The Maptask corpus (Gorisch et al. 2014) includes video recordings for both participants individually so as they could see each other during the dialogue. The Maptask corpus is a collaborative task in which speakers are directors or followers, round after round, and they have to track back a pathway on a paper. 4 pairs of participants performed seven map tasks and each map took about 5 minutes to complete. Participants were recruited at the LPL. They were researchers, post-doctoral researchers and master's degree students and knew each other. The corpus was recorded in an anechoic room. Each speaker was equipped with a microphone headset enabling the recording of both speakers' voices on different sound tracks in order to allow a fine-grained analysis of overlap phases, namely with regard to phonetics and prosody. The Maptask corpus exhibits a main activity of explanation and presents factual information concerning the direction and the location of elements on the map.

\section{The Corpus of Interactional Data}

The CID (Bertrand et al. 2008) is an audio video recording of French face-to-face conversations ( 8 pairs of speakers, 8 hours, about 115,000 words). Like for the previous 
corpus, the CID was recorded in an anechoic room and each speaker was also equipped with a microphone headset. The participants were asked to talk about either unusual situations ( 3 dyads) or contentious professional situations (5 dyads) in which they were involved.

Despite the task and the setting, the protocol was thought up to favor conversational interaction. On the one hand, not only all the participants were colleagues in the same University, but the members of each dyad were also friends used to meeting up outside work. On the other hand, bringing friends together for one entire hour left room for many digressions.

The advantage of using these two types of data for examining different manifestations of mutual understanding is linked to their different intrinsic nature (in terms of goal particularly), and their embedding in a different larger task.

\section{Method}

Using Praat (Boersma \& Weenink 2009) the speech signal of both corpora was presegmented into Inter-Pausal Units (IPU) defined as speech blocks punctuated by silent pauses of at least 200ms. IPUs are not linguistic units although some studies can be conceived them as turns (Koiso et al. 1998). In our work, they are formal objective units facilitating the subsequent manual orthographic transcription. From this transcription, both corpora were annotated at different linguistic levels (temporally aligned) (Blache et al. 2010; Prévot et al. 2016). The different phenomena investigated were systematically annotated on the whole corpus. After that, and as it is the case in this present paper, we propose a notation a posteriori of phenomena within the given transcription of extracts (see conventions in the end of the article).

In this paper, the main phenomenon concerns feedback items that were annotated for both corpora (for details see CoFee Project: http://cofee.hypotheses.org/). However, other different levels of annotation were used here. For the CID, we used the annotation level of stories (for details see Bertrand \& Espesser 2017). For the Maptask, we used the annotation level of eyebrow movements. Until now, only the Maptask was entirely annotated at this level. Examples considered here are extracted from Goujon (thesis, in preparation) who questions how participants can make a source or problems identifiable by focusing on eyebrow movements. On the one hand, this work aims at filling the gap concerning multimodal feedback responses (see Mondada 2011, 545). On the other hand, by focusing on eyebrow movements as a potential trigger of disalignment, this work also contributes fully to the scope of this paper, i.e.to enhance the knowledge of (mis)understanding and (dis)alignment relationship. The pre-segmentation and annotation of eyebrow movements were realized with the segmentation mode of ELAN (Sloetjes \& Wittenburg 2008). Eyebrow raises and frowns were manually annotated. In order to do so, it is necessary to watch the video at a slowed rate to find the exact image corresponding to the eyebrow movement. If it is an eyebrow-raising movement, the eyebrows gradually rise up and go 
back to a neutral position on a vertical axis. If it is a frowning movement, the eyebrows move horizontal axis. Eyebrows move toward each other near the center and a line appears between them. It is important to note that the annotated movements can be on a single eyebrow.

Given the objective of the thesis work, the annotation of sequences revealing a potential trouble in understanding was also performed. Among relevant cues for identifying such sequences, discourse markers such as "attends", "j'ai pas compris", "excuse moi” ("wait", "I didn't understand", "excuse me") and the presence of a repair sequence, both showing a break in the progressivity of discourse, were used. 84 sequences were extracted, among them 29 were produced with eyebrow movements. Three categories of sequences revealing a potential problem in understanding have been identified: non-comprehension and incomprehension cases (Weigand 1999), and a check for understanding case (Antaki 2012). Our following analysis will introduce a case of each category established in the Maptask. We will show what kind of specific disalignment cues participants use for indicating and/or solving a potential trouble in understanding within each category, first in the Maptask corpus, secondly in the CID.

Our approach is quite original since we adopted a hybrid method based on Corpus Linguistic approach and Conversation Analysis. Within a sequential analysis, the next-turn proof procedure (Hutchby \& Woofitt 2008) enables us to shed light how each turn is subsequently interpreted by the other participant, in regard to the prior and the next turn and how turn after turn (incrementally), participants demonstrate their mutual (mis)understanding (to each other).

\section{Analysis}

\subsection{Referential (dis)alignment and non comprehension}

The first level of understanding requires a referential alignment (cf. "situation model", Pickering \& Garrod 2004). A disalignment can be due to a lack of common referents.

The nature of a Maptask corpus is particularly suitable for investigating explanation activity at referential level since available references in each of maps are not similar between both participants. Indeed, the purpose of this type of task is to show how participants, step by step, construct their knowledge and, in most cases, successfully achieve the task. While the director gives instruction, the follower has to follow it despite their different map. The necessary collaborative achievement of this task involves a quasi turn-by-turn tracking. Ambiguity is something that such an Instruction task corpus can in no way afford (understanding needs to be checked at almost every turn). Thus although understanding may be tacit (Mondada 2011), it is mostly explicitly performed in such a corpus by using feedback responses as continuers/acknowledgements and agreements (mh, yeah, nod, repetitions). In this task, an aligning response would be a yes, ok, or an absence of response followed by the accomplishment of the instruction. 
The example (1) illustrates a non-comprehension case (Weigand 1999) due to a lack of knowledge by the recipient. Transcript conventions can be found at the end of this article.

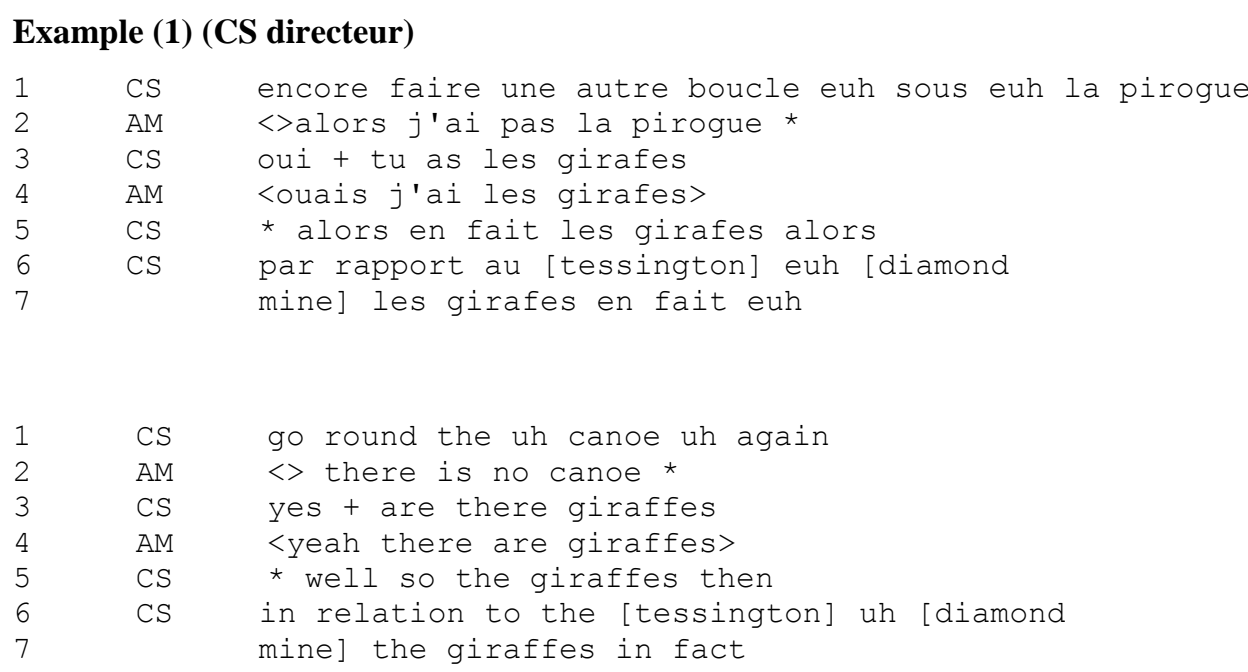

The trouble is immediately identified because the director gives a referent that does not exist on the follower's map. Thus, the follower immediately displays disalignment cues related to the lack of the same referent ('pirogue') in his own map. Disalignment cues combine both an eyebrow raising movement (conveying a function of surprise or doubt) and an explicit verbal utterance expressing the source of the trouble. We can see an immediate resolution from the director who, after taking this missing referent into account with the 'oui' (line 3) item, immediately suggests another referent. This latter is immediately ratified by the follower with a combined response composed of 'ouais' + repetition + eyebrow raising movement allowing participants to realign from this new element to go on with the task. Both eyebrow raising movements seem to function as formal boundaries of the reparation sequence.

Example (2) is extracted from the CID. We want to show here how participants can also try to align at a referential level in a conversation-style corpus in which implicit and ambiguous elements can be less dramatic than in a Maptask corpus. We show that when the interlocutor attempts to align at the referential level, she simultaneously conveys cues related to the intersubjective dimension revealing a larger collaborative activity that her partner may or may not take into account in the understanding process.

The extract (2) appears at the beginning of one interaction involving two females. In order to recount and share stories as agreed (i.e. tell unusual situations), participants attempt at aligning regarding the meaning of the term used, i.e. 'insolite'. However, among the 8 dyads of the corpus, only this one shows such an attempt of explicit initial alignment at a referential level before starting the dialog. 


\section{Example (2)}

\begin{tabular}{|c|c|}
\hline$A B$ & bah alors \\
\hline $\mathrm{CM}$ & * bon insolite allez cherche \\
\hline $\mathrm{AB}$ & l'insolite \\
\hline$A B$ & 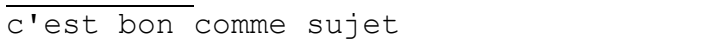 \\
\hline$A B$ & bah alors est-ce que je vais remonter \\
\hline $\mathrm{CM}$ & c'est ça n'évoque rien euh \\
\hline $\mathrm{CM}$ & $\begin{array}{l}\text { euh je suis pas sûre de con de bien } \\
\text { connâ̂tre la définition du mot }\end{array}$ \\
\hline $\mathrm{CM}$ & de euh \\
\hline $\mathrm{CM}$ & insolite \\
\hline$A B$ & $\begin{array}{l}\text { moi je peux prendre ça comme quelque } \\
\text { chose d'inhabituel inusuel } \\
\text { + qui a l'air assez }(0.736)\end{array}$ \\
\hline $\mathrm{CM}$ & ah oui inhabituel ouais \\
\hline $\mathrm{CM}$ & moi je verrais oui des choses \\
\hline $\mathrm{AB}$ & particulier \\
\hline$A B$ & aussi + particulier $(0.674)$ \\
\hline $\mathrm{CM}$ & $\overline{\text { où euh }}$ \\
\hline$A B$ & qui ne coule pas de source qui \\
\hline $\mathrm{CM}$ & oui où tu perds un peu euh tu perds un \\
\hline & peu comment dire $(0.981)$ \\
\hline $\mathrm{CM}$ & euh des repères quoi tu vois c'est à \\
\hline$A B$ & qui peuvent être extraordinaires \\
\hline$A B$ & $\mathrm{mh}$ \\
\hline $\mathrm{CM}$ & c'est euh ouais voilà ouais (1.260) \\
\hline $\mathrm{CM}$ & $\begin{array}{l}\text { alors a rien il m'est rien arrivé } \\
\text { d'insolite dans ma vie absolument rien } \\
\text { a (1.547) }\end{array}$ \\
\hline $\mathrm{CM}$ & euh \\
\hline$A B$ & tout était normal logique (0.358) \\
\hline $\mathrm{CM}$ & oui tout à fait a \\
\hline $\mathrm{CM}$ & insolite \\
\hline
\end{tabular}

${ }^{2}$ We recall that the corpus was segmented in Interpausal unit (IPU). The numbers following the initials (the speakers) correspond to this cut out. 


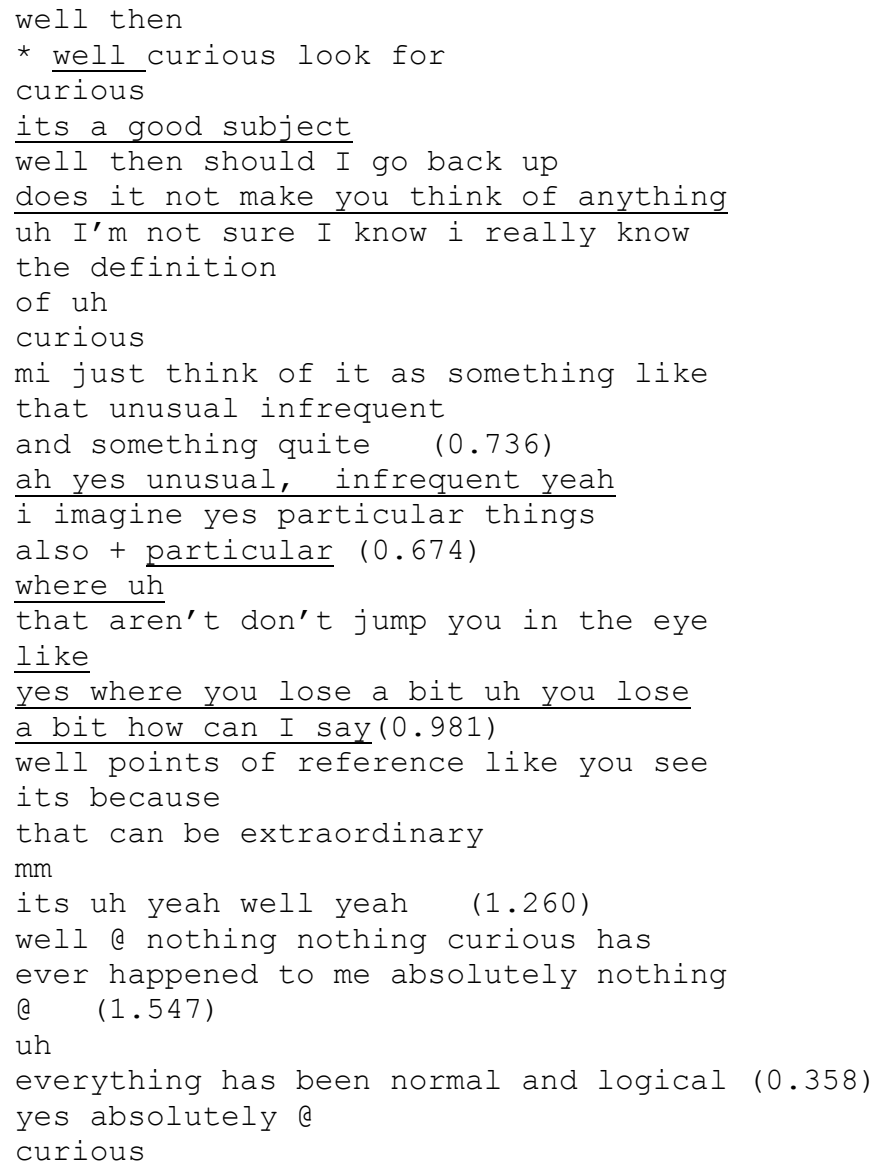

While $\mathrm{AB}$ (line 5) shows her intention to fulfill the request related to the corpus, i.e. starting a story, CM prevents her from starting by asking her what she means by the word 'insolite'. This question from CM postpones the core of the corpus, i.e. telling stories, but simultaneously shows an orientation to $\mathrm{AB}$ with whom she will now share referents to achieve a first level understanding (talking about the same things with the same term) that will ensure the success of their dialog. By opening this activity of explanation, CM disaligns with the previous action by which $\mathrm{AB}$ seemed to position herself as the next storyteller. However, neither of them really had speakership (vs the director/follower in the maptask) and CM (line 6) makes no hesitation in interrupting AB's projected action by displaying her state of affairs about the instruction (more particularly about the term 'insolite') in an overlap with AB's turn. Sequentially, her utterance projects an answerresponse even if she does not provide a direct question. We can see (line 11) that AB gives the expected (preferred) response, i.e. showing that she has understood the indirect demand: The adjacency pair (line 7-line 11) then respects the preference and conditional relevance principles (“an answer is conditionally relevant after a question”, Schegloff \& Sacks 1973) and perfectly fits with the sequential notion of understanding (Schegloff 1992). By providing complex feedback (line 14), composed of a change-of-state token 'ah oui' + other-repetition 'inhabituel' + an agreement 'ouais' overlapping with part of AB's turn, CM very clearly expresses her alignment with $\mathrm{AB}$ that reveals a perfect understanding. However, and although both participants seem henceforth aligned at a referential level and 
ready to involve in telling "unusual stories", they cannot do it: indeed, AB does not yield the floor without completing the definition. In doing so, she does not focus (she goes on to ignore it) on the feedback response provided by CM. Contrariwise, along with the three very long pauses $(13,17,21)$ in the middle of her turn, $A B$ illustrates to what extent she remains focused on her own discourse in 1/ projecting a more to come as if she was completely legitimate as main speaker and could pause without risking to loose the turn and 2/ also ignoring the clear demonstration of understanding from CM. The sequence (lines 15-24) then illustrates a kind of disaligned sequence in which both participants try to give their own definition in a most exhaustive way. Globally, it is noteworthy that while CM exhibited a more collaborative attitude by not only requesting a definition from $\mathrm{AB}$, but also by aligning with this definition, and finally by eliciting a cue of alignment from $\mathrm{AB}$ ('tu vois' line 22), AB does not even demonstrate such a cue. When she provides the minimal token 'mh' at the end of her explanation, $\mathrm{AB}$ seems to be merely ratifying her own prior explanation unlike CM (line 26) who rather seems to ratify their joint activity of definition. This initial explanation sequence, embedded in a larger activity of narrative conversation, illustrates the need for partners in conversation to share referents (referential alignment) for mutual understanding. However, it also reveals a participant (CM) very oriented to her partner (see Bertrand \& Espesser 2017 who showed that CM was one of the 'best' listeners) versus a less collaborative one $(\mathrm{AB})$. We may then wonder if $A B$ has really completely understood what CM did with her turn, e.g. showing her desire to collaborate with her partner without hesitating to convey a lack of order to collaboratively change the current state of affairs. For her part, $\mathrm{AB}$ demonstrates her understanding of the only referential lack: yet understanding is of course far from being a simple alignment at a referential level.

\subsection{Disalignment and incomprehension case}

The example (3) illustrates an incomprehension case (Weigand 1999) due to a misinterpretation of an utterance: the message sent by the speaker is not received properly.

\section{Example (3) (YM directeur)}

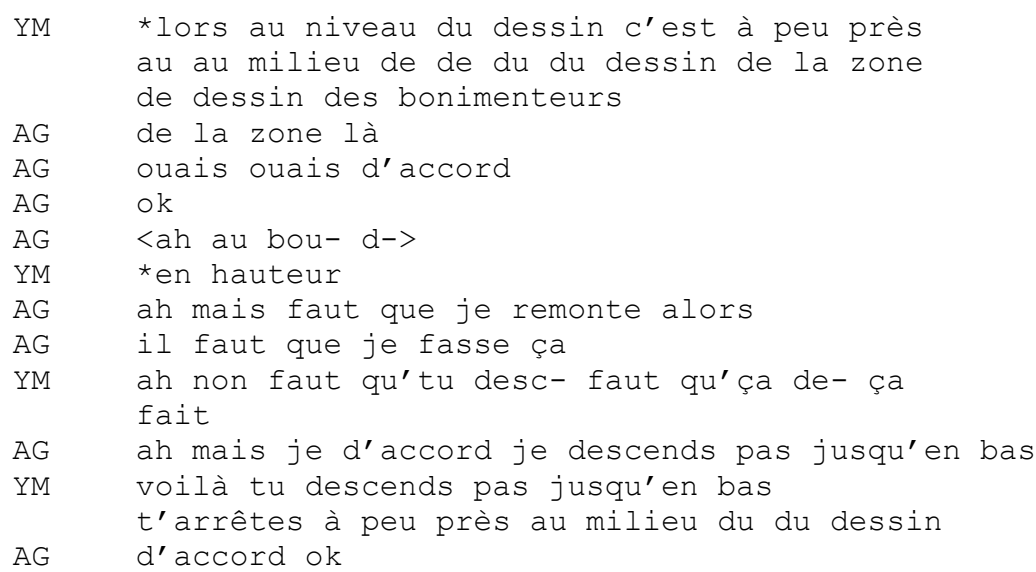




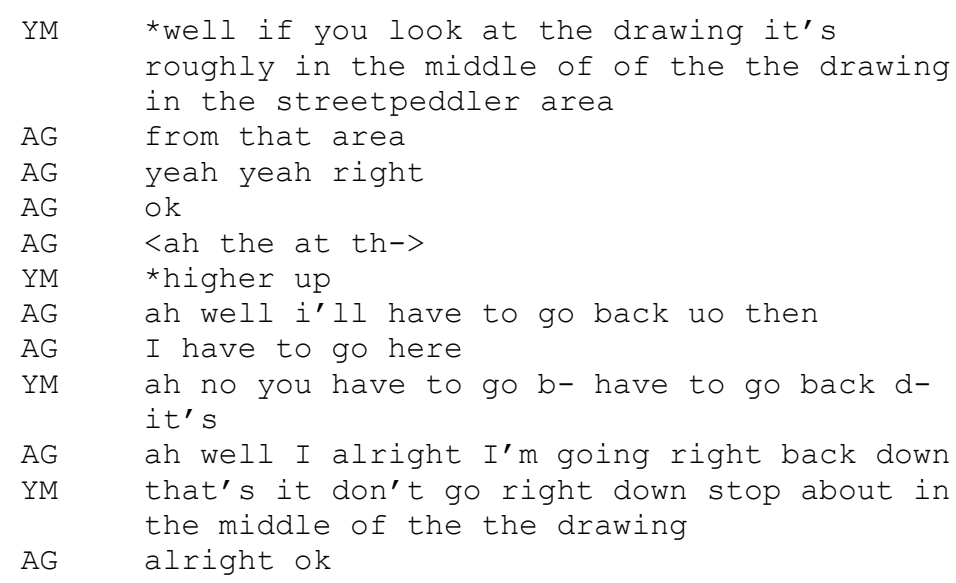

Here, once again the follower disaligns by providing a dispreferred response. But in this case, although sufficient information was available to understand what the director said, the follower misunderstood the location of the zone. The director cannot avoid the misunderstanding sequence that persists for several turns because the repair is not immediate. After several acknowledgement tokens, from line 7, AG produces a confirmation request initiated by a change-of-state token (ah) and associated with a raised eyebrow aiming at checking the understanding. These different cues conveying a form of surprise appear as the main trigger of disalignment. After that, the director's response (line 8) reveals the misunderstanding that will be followed by a long sequence of repair: As the trouble source of repair, the utterance line 9 (with another confirmation request, still initiated by a change-of-state token 'ah') marks the beginning of the incomprehension sequence. Then the director gives a repair solution (line 11), after which the follower shows comprehension of the trouble source. The ratification of repair solution ("d'accord ok") is given in line 18. This example is an illustration of the explicit achievement from misunderstanding to understanding (see also the reiteration of the same change-of-state token 'ah' conveying surprise or doubt at each step of the repair sequence), after a first step of disalignment. The last step of realignment occurs when the follower ratifies (line 18) the repair of the director resulting in mutual understanding.

The Example (4) illustrates a typical incomprehension case in conversation storytelling. In a recent paper about listing practice in storytelling (Bertrand \& Priego-Valverde 2017), we have shown that a list item added by a recipient within a list produced by a storyteller, can be considered the best candidate for showing a mutual understanding. However, this list item is considered an appropriate/aligned response if it occurs at the right place at the right time. The example (4) (extracted from Bertrand \& Priego-Valverde 2017) shows how the recipient of the list embedded in a story failed to understand that she had not yet the legitimacy for providing his/her response.

\section{Example (4)}




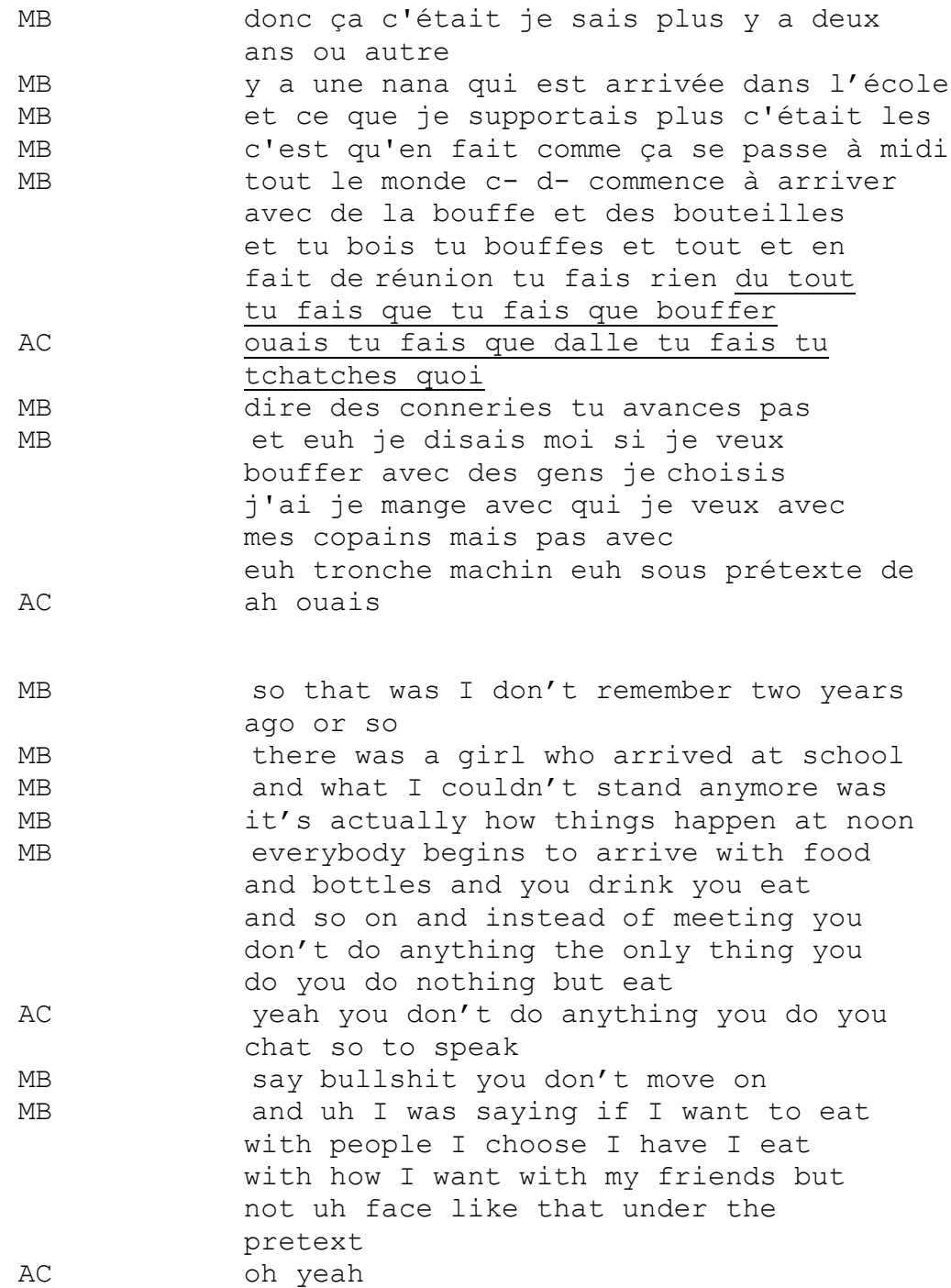

MB tells a story concerning her work and the bad habit (according to her) her colleagues have of scheduling meetings at lunchtime. She explains that such a schedule is totally counterproductive and she initiates a list in which each item is proof of this counter productivity. The rude manner in which $\mathrm{MB}$, the main speaker, shows she wants to continue speaking (line 13) by ignoring the list item from AG (line 11-12), can be explained by the fact that $\mathrm{MB}$ is engaged in the orientation phase of her story (at the beginning). The goal of the two lists she produced just previously is not to illustrate something she had already said, which could have allowed the listener to co-elaborate the discourse, at very least to show her agreement, but to present the characters and circumstances of events in the story and then prepare the ground for establishing her own opinion and justify it. This list item from AG occurred too early for MB who considered it a disaligned response. Her lack of ratification here provides special access to (mis)understanding. This is totally in line with Stivers about nodding (2008) or Selting about laughter (2017) for whom a response occurring too early (or too late) reveals a disalignment and a problem in understanding. 
The following example (5) illustrates another case of the relationship between (dis)alignment and understanding. This is a case of storytelling in which the recipient punctually disaligns at the beginning of the story.

The extract is related to two males. Following the instructions (to tell stories of professional conflict), it is the first story of the dialog. When he was in Belgium, EB worked with a colleague on developing computer softwares. The conflict was not about the content but about the form. His colleague wondered whether they had to use upper or lower case letters, which was absolutely ridiculous for EB.

\section{Example (5)}

$\mathrm{EB}$

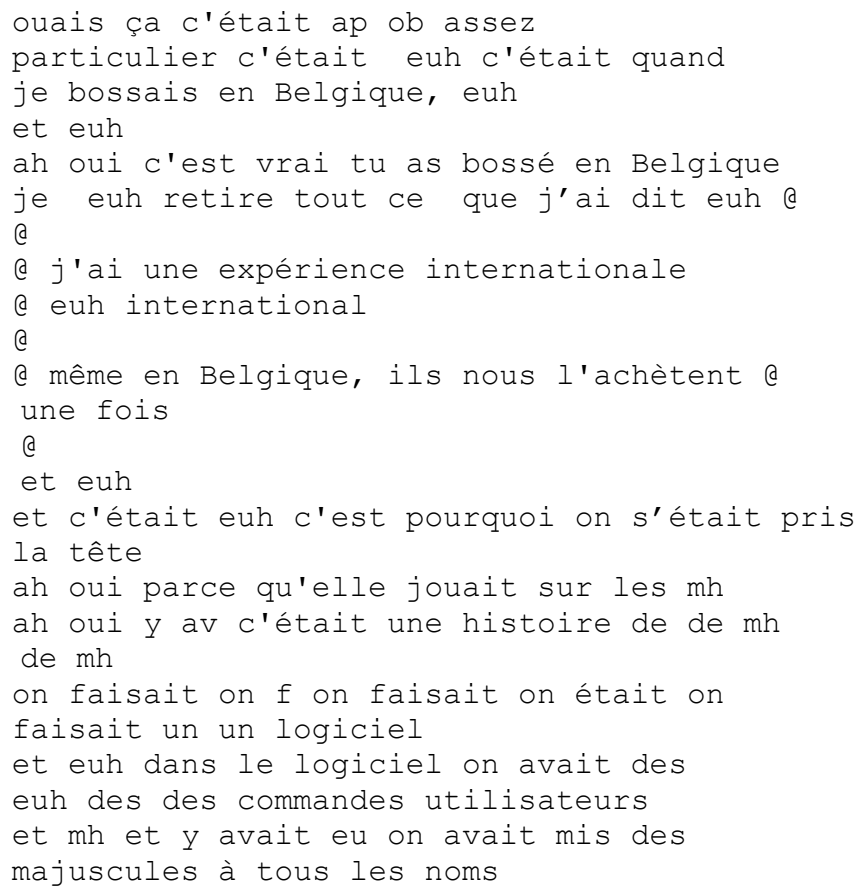


EB starts his story by displaying deictic elements usually used in the orientation phase to introduce a story. Immediately, while such a deictic element in storytelling was not intended for discussion, it is here used by SR for disaligning (line 5). Previous studies (Bertrand \& Priego-Valverde 2011; Guardiola \& Bertrand 2013) have shown that typical responses such as other-repetitions or echo reported speech can be relevant cues for introducing a new tonality or a new frame. However this more frequently happens in the middle or at the end of the story when both participants have all information allowing them to understand and evaluate it. By initiating this unexpected response here, SR does not show a lack of understanding from the recipient. Far from introducing repair, on the contrary he reacts on the content word in order to detract it from its focus while claiming his intention to make fun of the current story. This reflects what is being performed in the whole dialog task even if SR will respect the instruction throughout the interaction.

$\mathrm{EB}$, as main speaker, does not only agree to engage in this new frame but overbids (line 78) on SR's proposal resulting in a side humorous sequence (Jefferson 1972).

Then, after an initial disalignment from recipient, we can also observe a fully aligned sequence (depending on whether the main speaker aligns or not) showing a perfect mutual understanding achievement.

In our opinion, this disalignment could mean that the leadership of the teller can sometimes be delayed, more particularly in conversation. This delay can be considered a resource for indicating that the recipient is not a passive listener in orienting the interaction in a specific way.

\subsection{Disaligning for checking understanding}

Check for Understanding cases (Antaki 2012) are produced in order to anticipate potential misunderstandings. These are polar questions which appear in a morally problematic situation (Stivers et al., 2011). The questions have an interrogative structure but their content is partially asserted.

\section{Example (6) (AM directeur)}

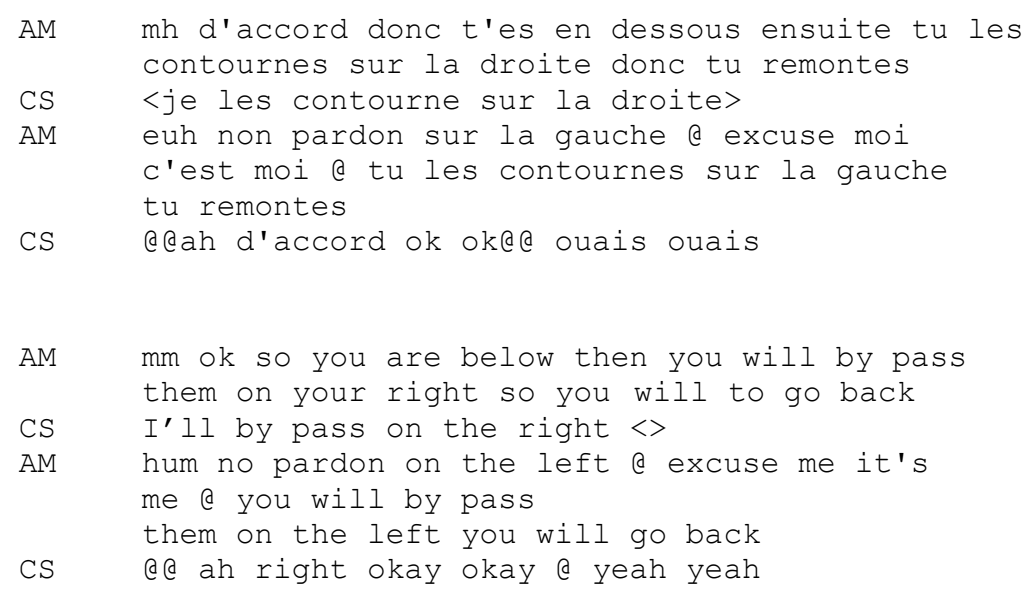


Among the responses, other than simple continuer provided by the follower, otherrepetitions (as confirmation request), can be used to Check For Understanding (CFU). The example (6) shows such a CFU (associated with eyebrow movements at its beginning and its end) allowing the director to realize his error. A self-initiated repair is then performed to avoid failure of comprehension. Feedback response from CS shows not only that he has correctly understood the repaired turn but also that he had anticipated a potential trouble before expressing his CFU given that the function of this feedback (change-of-state $=>$ ' $a$ h d'accord' line 7, that we could paraphrase as 'I thought so! That's strange').

Example (7) involving the same pair of female speakers of (2) again illustrates how one participant uses disalignment as a resource for signalizing another form of understanding related to the speakers' relationship in real life.

\section{Example (7)}

$1 \mathrm{AB}$

$\mathrm{CM}$

AB

CM

$\mathrm{CM}$

$\mathrm{CM}$

AB

$\mathrm{CM}$

$\mathrm{CM}$

AB

$\mathrm{CM}$

$\mathrm{CM}$

$\mathrm{AB}$

$\mathrm{AB}$

$\mathrm{CM}$

AB

$\mathrm{CM}$

AB

$\mathrm{CM}$

AB

CM

CM

$\mathrm{CM}$

$A B$

$\mathrm{CM}$

$\mathrm{CM}$

AB

CM

$\mathrm{CM}$

AB

$A B$

$\mathrm{CM}$

$\mathrm{AB}$

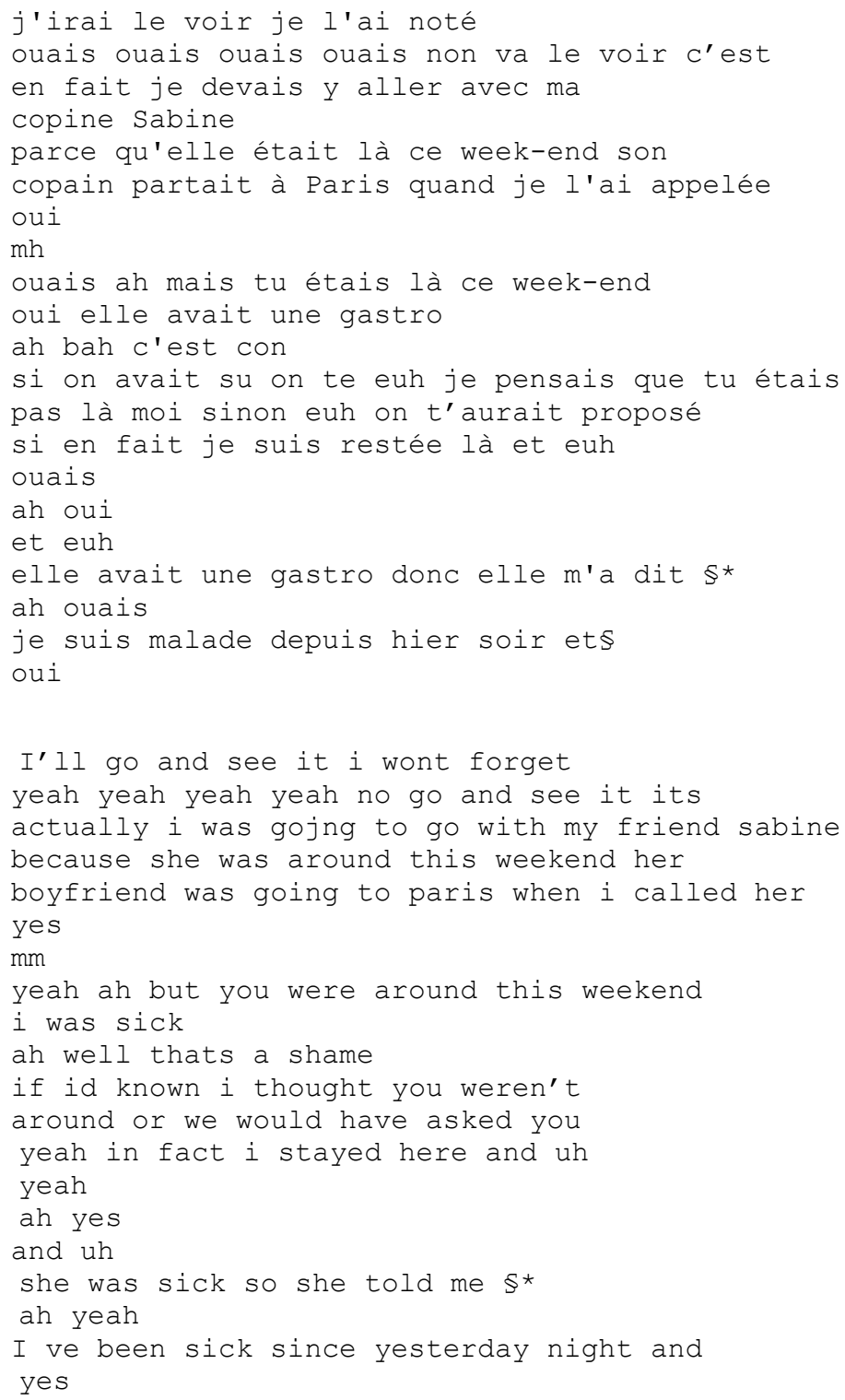


This extract just follows a discussion about a movie that $\mathrm{CM}$ has seen and has just described to $A B$. The latter seems to have appreciated it since she starts by saying ' $j$ 'irai le voir je l'ai noté' (line 1). Just after this, AB starts to relate why she might not be able to go to see it. She projects a story and immediately $\mathrm{CM}$ aligns as recipient by providing three continuers before understanding that $\mathrm{AB}$ had been around that weekend. By creating a failure in the progressivity of the activity projected by AB ('je l'ai appelée'), $C M$ (line 9) disaligns. This disalignment however, is neither a means of initiating repair nor of threatening $\mathrm{AB}$ but rather a means for $\mathrm{CM}$ to show to what extent she has understood what $\mathrm{AB}$ just said and the potential future implications about their relationship: $\mathrm{AB}$ had been there this weekend and CM did not call her to invite her to join them. By disaligning to justify herself, CM displays a demonstration (Sacks 1974) of her understanding. Once again, although $\mathrm{AB}$ 's turn respects the conditional relevance implying an answer-response here, she fulfills it minimally with a simple 'oui' before going on with her story. CM however does not give up and provides another component aiming at evaluating this answer and justifying herself. AB's turn confirms her answer (aligns) but minimally ("yes she was here" but she does not provide more for showing that she does not hold it against $\mathrm{CM}$ ). The sequence ends with the minimal acknowledgment provided by $\mathrm{CM}$ who now lets $\mathrm{AB}$ going on with her story. By repeating the prior phrase 'elle avait une gastro' AB shows her realignment with her initial story. At this point, $\mathrm{CM}$ accepts and (once again) becomes recipient enabling the progressivity of the story (lines 19 and 21).

The disalignment from CM can be explained by several reasons: First, it is not the kind of story requested by experimenters; Secondly, we know that CM is one of the best listeners of the CID providing a lot of feedback when necessary. By choosing to disalign, CM gives evidence that the relationship between herself and $\mathrm{AB}$ in real life is more important than the structural format required when a story is projected.

\section{Elements of conclusion}

Using the notion of alignment/disalignment proposed by Stivers (2008), we claim that mutual understanding covers a larger acceptation than what is traditionally admitted. In such a conversationalist perspective indeed, mutual understanding is not conceived as a cognitive individual process but rather as a collective and collaborative activity (Mondada 2011). Mutual understanding does not only refer to the meaning of the words or sentences exchanged but to the meaning/comprehension of actions and activities in which participants are involved as well as the different positions and stance they adopt towards each other. Feedback responses play a crucial role in the achievement of mutual understanding. However, as unexpected responses, they can be used as triggers of disalignment and can reveal a potential trouble or problem of understanding. The examination of different sequences of storytelling and explanation embedded in larger tasks (conversation or instruction task) enables us to better understand why and how some typical feedback 
responses can disalign for some times initiating a repair but also for conveying other levels of understanding dealing with intersubjectivity.

In the Maptask corpus, we highlighted typical cues of disalignment, e.g. eyebrow movements and change-of-state token ("ah") both expressing a form of surprise, that more or less lead to a repair sequence. In this case, such disaligned responses require stopping or postponing the accomplishment of the instruction. By disaligning, the follower shows this problem leading the director to repair it. The repair sequence can then be an explicit way to (re)align. Given the nature of such a corpus, it is crucial to understand each other for achieving the task in a successful way. Participants can then disalign for expressing 'noncomprehension' (Weigand 1999) dealing with a referential disalignment, or for expressing 'incomprehension' (Weigand 1999) dealing with a misinterpretation of discourse. 'Checking for understanding' (Antaki 2012), produced for anticipating a potential trouble in understanding, can also cause a disalignment potentially followed by a repair.

The examination of the conversational corpus (CID) shows that if similarly disalignment cues aim at preventing a potential misunderstanding namely due to a referential lack, participants can use referential alignment as a resource for conveying a level of understanding related to the interaction itself and to the relationship between both participants. Furthermore, recipients can also use a disaligned response as a resource for orienting the interaction in a particular frame (for example humor) showing that he/she has well understood what is going on but more importantly that he/she is a real actor and not a passive listener for achieving current activity/interaction in a successful way. Finally, recipients can also provide an inappropriate response because occurring too early. In this case, the lack of ratification of this response makes it a disaligned one and points out misunderstanding related to the current activity (Stivers 2008; Selting 2017; Bertrand \& Priego-Valverde 2017).

To conclude, this notion of (dis)alignment really seems to be a relevant conceptual tool to improve our knowledge on how participants mutually show each other (mis)understanding. Future research including more specifically facial movements as potential cues or triggers of (dis)alignment could be conducted in a more systematic way thanks to large databases now available. More globally, further research could improve knowledge about more global disalignment cues in order to implement them into virtual conversational agent studies.

\section{Transcript conventions}

Elision: the characters related to the omitted phonemes are written between parentheses: "petit" pronounced /pti/ is noted p(e)tit.

Truncated words: annotated with a final dash.

le li- le livre (the book).

Missing liaisons : \# trois \# amis (missing required liaison)

Onomatopoeia: the typical back-channel onomatopoeia $/ \mathrm{m} /$ produced by the hearer is transcribed as mh when it was realized with one syllable, and mhm for two syllables. 
Incomprehensible sequences annotated with a star: *

Laughters: @

Said while laughing:@@...@@

Pauses: long pauses (more than 200ms) are automatically detected and enable to identify IPU. The shorter perceptible pauses are notated with “+” and very long pauses are sometimes indicated in the transcript $(0.700 \mathrm{~ms})$

Overlaps: the words or utterances in overlapped were underlined

bah alors est-ce que je vais remonter

c'est ça n'évoque rien euh

[...] refer to the entity on the maptask

\section{Eyebrow movement}

$<>$ fast eyebrow movement

$<\ldots>$ eyebrow movement occurring on the whole segment

\section{Acknowledgments}

The authors wish to thank Béatrice Priego-Valverde and two anonymous reviewers for their comments and feedback on the present paper.

\section{References}

Allwood, J., Cerrato, L., Jokinen, et al. (2007). The MUMIN coding scheme for the annotation of feedback, turn management and sequencing phenomena. Language Resources and Evaluation, 41(3): 273-287.

Antaki, C. (2012). Affiliative and disaffiliative candidate understandings. Discourse Studies, 14(5), 531-547.

Atkinson, J.M. (1992). Displaying neutrality: formal aspects of informal court proceedings. In Drew \& Heritage (eds.), Talk at work: interaction in institutional settings, Cambridge, 199-211.

Bavelas, J.B., Coates, L., Johnson, T. (2000). Listeners as co-narrators. Journal of Personality and Social Psychology, 79, 941-952. http://dx.doi.org/10.1037/0022$\underline{3514.79 .6 .941}$

Bertrand, R., Blache, P., Espesser et al. (2008). Le CID -Corpus of Interactional DataAnnotation et Exploitation multimodale de Parole Conversationnelle. Traitement Automatique des Langues, 49, 105-134.

Bertrand, R. \& Priego-Valverde, B. (2011) Does prosody play a specific role in conversational humor? Special Issue of Pragmatics and Cognition, 19, 2, 333-356.

Bertrand, R. \& Espesser, E. (2017). Co-narration in French conversation storytelling: A quantitative insight. Journal of Pragmatics, 111, 33-53.

Bertrand, R. \& Priego-Valverde, B. (2017). Listing practice in French conversation: From collaborative achievement to interactional convergence. Discours [En ligne], 20|2017, URL : http://discours.revues.org/9315 ; DOI : 10.4000/discours.9315 
Blache, P., Bertrand, R., Bigi, B. et al. (2010). Multimodal annotation of conversational data. In Proceedings of the Fourth Linguistic Annotation Workshop, ACL, 186-191.

Boersma, P. \& Weenink, D. (2009). Praat: Doing Phonetics by Computer (Version 5.1.05)

[Computer Program]. Available from: http://www.praat.org/

Bunt, H. (1994). Context and dialogue control. Think Quarterly, 3(1), 19-31.

Clark, H.H. (1996). Using Language. Cambridge University Press, Cambridge.

Clark, H.H. \& Fox Tree, J.E. (2002). Using $u h$ and $u m$ in spontaneous speaking. Cognition, 84, 73-111.

Dittman, A. \& Llewellyn, L. (1968). Relationship between vocalizations and head nods as listener responses. Journal of Personality and Social Psychology, 9 (2), 79-84.

Duncan, S. \& Fiske, D. (1977). Face-to-face Interaction: Research, Methods and Theory. Hillsdale, Lawrence Erlbaum.

Fishman, P. (1983). Interactions: The work women do. In Thorne, B., Kramarae, C., Henley, N. (eds.), Language, Gender and Society, Rowley: Newbury House, 89-101.

Gardner, R. (2001). When Listeners Talk. John Benjamins Company.

Garrod, S. \& Pickering, M.J. (2009). Joint Action, Interactive Alignment, and Dialog. Topics in Cognitive Science 1, 292-304.

Goujon, A. (thesis, in preparation). Indices d'incompréhension et séquences de réparation dans l'interaction en face-à-face: une analyse multimodale. Aix-Marseille Université. France.

Goodwin, C. (1986). Between and within: Alternative sequential treatments of continuers and assessments. Human Studies, 9, 205-217.

Gorisch, J., Astésano, C., Bard, E. et al. (2014). Aix Map Task corpus: The French multimodal corpus of task-oriented dialogue. In Proceedings of the Ninth International Conference on Language Resources and Evaluation (LREC 14), Reykjavik, Iceland.

Gravano, A. \& Hirschberg, J. (2011). Turn-taking cues in task-oriented dialogue. Computer Speech and Language, 25 (3), 601-634.

Guardiola, M. \& Bertrand, R. (2013). Interactional convergence in conversational storytelling: when reported speech is a cue of alignment and/or affiliation. Frontiers Cognitive Sciences, $30 \mathrm{p}$.

Jefferson, G. (1972). Side sequences. In D.N. Sudnow (Ed.) Studies in social interaction. New York, NY, Free Press, 294-33.

Holmes, J. (1997). Story-telling in New Zealand women's and men's talk. In Wodak R. (ed), Gender and Discourse, London, Sage, 263-293.

Hutchby, I. \& Woofitt, R. (2008). Conversation Analysis: Principles, practices, and applications $\left(2^{\text {nd }}\right.$ ed.). Cambridge University Press.

Koschmann, T. (2011). Understanding understanding in action. Journal of Pragmatics, 43, 435-437. 
Koiso, H., Horiuchi, Y., Tutiya, S. et al. (1998). An analysis of turn-taking and backchannels based on prosodic and syntactic features in Japanese Map Task dialogs. Language and Speech, 41 (3-4), 323-350.

Lindström, A. \& Sorjonen, M.L. (2014). Affiliation in conversation. In Sidnell, J., Stivers, T. (Eds.), The Handbook of Conversation Analysis. Blackwell, 350-369.

Mondada, L. (2011). Understanding as an embodied, situated and sequential achievement in interaction. Journal of Pragmatics, 43, 542-552.

Oloff, F. (2014). L'évaluation séquentielle des complétions collaboratives : analyse séquentielle et multimodale de tours de parole co-construits. Congrès Mondial de Linguistique Française, 2125-2145.

Pickering, M. \& Garrod, S. (2004). Toward a mechanistic psychology of dialogue. Behavioral and Brain Sciences 27,169-190. doi: 10.1017/S0140525X04000056

Prévot, P., Gorisch, J., Bertrand, R. (2016). A CUP of CoFee: A large Collection of feedback Utterances Provided with communicative function annotations. 10th edition of the Language Resources and Evaluation Conference, Portorož (Slovenia).

Sacks, H., Schegloff, E.A., Jefferson, G., (1974). A simplest systematics for the organization of turn-taking for conversation. Language, 50, 696-735.

Sacks, H. (1992). In Jefferson, G. (Ed.), Lectures on Conversation, vol. 2. Blackwell, Oxford.

Schegloff, E.A. \& Sacks, H., (1973). Opening up closings. Semiotica, 8, 289-327.

Schegloff, E.A. (1982). Discourse as an interactional achievement: some uses of "uhhuh" and other things that come between sentences. In Tannen (Eds.), Analyzing Discourse: Text and Talk. Georgetown University Press, Washington, DC, 71-93.

Schegloff, E.A. (1992). Repair after next turn: the last structurally provided for place for the defence of intersubjectivity in conversation. American Journal of Sociology, 95 (5), 1295-1345.

Selting, M. (2017). The display and management of affectivity in climaxes of amusing stories. Journal of Pragmatics, 111, 1-32.

Sinclair, J. \& Coulthard, M. (1975). Towards an analysis of discourse: The English used by Teachers and Pupils. London: Oxford University Press.

Sloetjes, H. \& Wittenburg P. (2008). Annotation by category - ELAN and ISO DCR. In Proceedings of the 6th International Conference on Language Resources and Evaluation (LREC 2008).

Stivers, T. \& Robinson, J.D. (2006). A preference for progressivity in interaction. Language in Society, 35(3), 367-392.

Stivers, T. (2008). Stance, alignment, and affiliation during storytelling: when nodding is a token of affiliation. Research on Language and Social Interaction, 41, 31-57.

Stivers, T., Mondada, L., Steensig, S. (2011). The morality of knowledge in conversation. Cambridge University Press. 
Ward, N. \& Tsukahara, W. (2000). Prosodic features which cue back-channel responses in English and Japanese. Journal of Pragmatics, 23, 1177-1207.

Weigand, E. (1999). Misunderstanding: The standard case. Journal of Pragmatics, 31(6), 763-785.

Yngve, V.H. (1970). On getting a word in edgewise. In Campbell, M.A. (Ed.), Papers from the Sixth Regional Meeting. Chicago Linguistics Society, Department of Linguistics, University of Chicago, Chicago, 567-578.

Roxane Bertrand, Laboratoire Parole et Langage, Aix Marseille Université, CNRS 5 Avenue Pasteur, 13100 Aix-en-Provence, France

Tel: +33(0)4 13553629

roxane.bertrand@univ-amu.fr

Aurélie Goujon, Laboratoire Parole et Langage, Aix Marseille Université, CNRS

5 Avenue Pasteur, 13100 Aix-en-Provence, France

Tel : +(33) (0)4 13555733

aurelie.goujon@univ-amu.fr 